\title{
Germanica
}

\section{Die Meister aus Deutschland. Zu Paul Celans}

\section{Todesfuge}

Les maîtres de l'Allemagne. Considérations sur le poème Todesfuge de Paul Celan.

\section{Alwin Binder}

\section{OpenEdition}

\section{Journals}

Édition électronique

URL : http://journals.openedition.org/germanica/1471

DOI : 10.4000/germanica. 1471

ISSN : 2107-0784

\section{Éditeur}

Université de Lille

\section{Édition imprimée}

Date de publication : 30 décembre 1997

Pagination : 51-71

ISBN : 977098426320321

ISSN : 0984-2632

Référence électronique

Alwin Binder, «Die Meister aus Deutschland. Zu Paul Celans Todesfuge », Germanica [Online], 21 | 1997, Online erschienen am: 05 Juni 2012, abgerufen am 06 Oktober 2020. URL : http://

journals.openedition.org/germanica/1471; DOI : https://doi.org/10.4000/germanica.1471

Ce document a été généré automatiquement le 6 octobre 2020.

(c) Tous droits réservés 


\section{Die Meister aus Deutschland. Zu Paul Celans Todesfuge}

Les maîtres de l'Allemagne. Considérations sur le poème Todesfuge de Paul Celan.

Alwin Binder

Die tausendmal abgedruckte " Todesfuge » ist von niemandem je verstanden worden. Auch von Celan selbst nicht. (Günther Anders) ${ }^{1}$.

Das Bürgertum, das die Mörder gestellt hatte, entlastete sich mit solchen Gedichten, die gleich

Beschwörungsformeln in guten Stuben und Vortragssälen gemurmelt wurden. (Peter Hartling) ${ }^{2}$.

Als Christ glauben Sie, daß selbst jemandem wie Ihrem Vater [dem Sekretär des Führers, Martin Bormann], wenn er Reue gezeigt hätte, seine Taten vergeben werden. - Das ist gut biblisch begründet, und zwar schon im Alten Testament, beim Propheten Jesaja : « Und seien Eure Sünden rot wie Blut, ich werde Euch weißer waschen als den Schnee $»^{3}$.

$\mathrm{Zu}$ kaum einem anderen deutschen Gedicht dürfte es so viele Interpretationen geben wie zu Paul Celans Todesfuge. Und die meisten sollen verdeutlichen, was Paul Celan mit diesem Gedicht beabsichtigte. Man vermag aber kein Gedicht zu verstehen, wenn man das herausfinden will, was sein Autor mit dem Gedicht sagen wollte, und wenn man am subjektiven Erfahrungshorizont dieses Autors mißt, ob eine Aussage über sein Gedicht richtig oder falsch sein kann. Die Sprache eines Autors ist nicht seine private Sprache, und jeder, der Bedeutendes sagt, sagt mehr, als er im Moment des Sagens weiß. Dementsprechend zeigt die Rezeptionsgeschichte der Todesfuge, daß Paul Celan von dieser Rezeption überrascht war und es ihn irritierte, daß die Todesfuge als das Gedicht fungierte, womit im Nachkriegsdeutschland der Holocaust aufgearbeitet werden 
konnte. Die Irritation Celans braucht nicht zu verwundern, da sein Gedicht fast ausschließlich aus Zitaten besteht, von denen möglicherweise andere Assoziationen angeregt wurden, als sie der Zitierende erwarten konnte. Die Formulierung « Schwarze Milch » schrieb Rose Scherzer-Ausländer in einem Gedicht von 1939, und die anderen zentralen Motive sind vorformuliert in dem 1944 entstandenen Gedicht Er von Immanuel Weißglas :

Wir heben Gräber in die Luft und siedeln Mit Weib und Kind an dem gebotnen Ort. Wir schaufeln fleißig, und die andern fiedeln, Man schafft ein Grab und fährt im Tanzen fort.

ER will, daß über diese Därme dreister Der Bogen strenge wie sein Antlitz streicht : Spielt sanft den Tod, er ist ein deutscher Meister, Der durch die Lande als ein Nebel schleicht. $[\ldots]$

ER spielt im Haus mit Schlangen, dräut und dichtet, In Deutschland dämmert es wie Gretchens Haar.

Das Grab in Wolken wird nicht eng gerichtet :

Da weit der Tod ein deutscher Meister war ${ }^{4}$.

Die Todesfuge ist montiert vor allem aus Gedanken, die der künstlerischen „Bewältigung“ des Holocaust dienen, so daß in ihr eher die Rezeption des Holocaust als dieser selbst gestaltet ist. Im Hinblick auf diese Rezeption werde ich fragen: Welche Entschuldungs-, Entlastungs-, aber auch Bewunderungsangebote enthält das Gedicht für die deutschen Rezipienten hinsichtlich des Holocaust? Welche ideologischen Bedingungen für eine solche Rezeption spiegelt das Gedicht wider? Ist das Gedicht zugleich eine Satire auf die in ihm vorgeführte und mit ihm angebotene Rezeption? Ich konzentriere mich vor allem auf die Aussage: "Der Tod ist ein Meister aus Deutschland », weil sich vermutlich darauf die Faszination ${ }^{5}$ der Todesfuge bezieht. Diese Faszination ist so zu denken, daß der Faszinierte selbst nicht weiß, was ihn „in Wirklichkeit" fasziniert. Er mag auf die Frage « Worum geht es in der Todesfuge ? » mit Stiehler antworten : «Thema ist das Leiden in den Konzentrationslagern. » ${ }^{6}$.

2 Voraussetzung dafür, «das Leiden in den Konzentrationslagern » als das Hauptthema des Gedichts zu sehen, ist die einhellige Auffassung, die Todesfuge werde von einem "wir », nämlich von den Opfern des «Mannes » gesprochen. Tatsächlich gibt es verhältnismäßig wenige Stellen, die vom « wir » gesprochen sein müssen: Das sind alle wörtlichen Aussagen im Zusammenhang mit "wir trinken » und "wir schaufeln", sowie « er befiehlt uns » und « er hetzt seine Rüden auf uns er schenkt uns ein Grab in der Luft ». Und auch die wörtliche Rede des « Mannes » ist nicht immer eindeutig : zum Beispiel braucht in Vers 24 «der Tod ist ein Meister aus Deutschland » nicht vom « er » gesprochen zu sein. Dagegen können Aussagen wie er «träumet der Tod ist ein Meister aus Deutschland» nicht unmittelbar vom «wir » stammen. Deshalb ist es sinnvoller, als lyrisches Subjekt einen Erzähler zu sehen, der die Welt des Gedichts erzählt und "wir» und den "Mann» sprechen läßt. Wenn ein Rezipient dies - bewußt oder unbewußt - wahrnimmt, verlieren die Aussagen des Textes ihre Unmittelbarkeit, da dieser Erzähler von einem höheren Standpunkt aus das Geschehen arrangiert. Am Erzähler könnte ablesbar sein, wie man Geschehnisse des Holocaust zusammen-'fügen' muß, damit er 'genießbar' wird. 
Bemerkenswert ist auch, daß in diesem Gedicht « wir » und «Juden » nicht identisch sind. «Er pfeift seine Juden hervor » wie « seine Rüden ${ }^{7}$, sie scheinen zum Haus zu gehören, werden wie Tiere behandelt und zu einer Handlung eingeteilt, die der von Totengräbern entspricht. Diesen " einen » sind die " andern » gegenübergestellt, die die Herstellung des (Massen-)Grabes künstlerisch begleiten. Indem das «wir » zu den " andern », also nicht zu den "Juden» gehört, eröffnen sich die verharmlosenden Rezeptionsmöglichkeiten, daß nicht nur Juden in den Konzentrationslagern gewesen seien und daß die «Juden» zwar hart arbeiten mußten, aber nicht vergast und dann verbrannt worden seien, weil sonst das Ausheben eines Grabes in der Erde sinnlos sei. Das « Grab in den Wolken » kann dann gesehen werden als Luftgespinst, als Schall und "Rauch». Durch die Unbestimmtheit des « wir » werden die Aussagen mehrdeutiger und verschwommener. Der "Mann » befiehlt beiden Gruppen und scheint beide mit den Rüden zu bedrohen, aber nicht nur die befohlenen Tätigkeiten sind verschieden, sondern auch der Umgang mit den "einen » und den "andern ». Während von den «Juden » nur Leistungssteigerung verlangt wird, sollen die " andern » nicht nur süßer und dunkler spielen und streichen und damit eine Todessehnsucht wecken, sondern ihnen sagt der "Mann», welche Folgen ihr gesteigertes Spielen für sie selbst haben werde : "dann steigt ihr als Rauch in die Luft dann habt ihr ein Grab in den Wolken ». Das klingt wie: „dann bekommt ihr, was ihr euch gewünscht habt“. Als Höhepunkt dieser Perversion, daß die Entmenschlichten dankbar sein müssen, fungiert die wörtliche Rede des « wir » : « er hetzt seine Rüden auf uns er schenkt [!] uns ein Grab in der Luft».

Möglich wird diese Perversion, weil der « Mann » so erzählt wird, daß er als „höhere“ Instanz, nämlich als Tod erscheint. Nach alten Vorstellungen sammelt der Tod die Menschen zum " $\operatorname{tanz}$ des todes und der toten » und spielt ihnen dazu auf8. Indem er « uns» zum Totentanz aufspielen läßt, erhebt er diese Menschen, und indem sie anstelle des Todes zum Tanz aufspielen, sind sie eingereiht in die Verantwortung für das Töten. Im Gedicht ist das Hochstilisieren des «Mannes» zu einer Allegorie des Todes schon angedeutet in dem Satz : " er greift nach dem Eisen im Gurt er schwingts ». Dieses "schwingts" hat im Zusammenhang mit einem "Schieß-Eisen“ wenig Sinn, vielmehr ist mit dem «Eisen» (synekdochisch, aber auch anagrammatisch ${ }^{9}$ : SENSE < EiSEN) zugleich die Sense des Todes gemeint. Noch deutlicher geschieht die Verwandlung des "Mannes" in den Tod mit den Aussagen "seine Augen sind blau » und «der Tod ist ein Meister aus Deutschland sein Auge ist blau». Das meisterhafte Zielen, das hier beschrieben wird, erscheint nicht nur im einzigen Endreim ${ }^{10}$ dieses Gedichts, «blau » und « genau », sondern noch dadurch gesteigert, daß in " genau » das " Auge » anagrammatisch enthalten ist (GEnAU < AUGE). Diese Perfektion enthält das Angebot an den deutschen Rezipienten des Gedichts, sich mit dem Können des Todesschützen $\mathrm{zu}$ identifizieren und den Mord am einzelnen entweder dadurch $\mathrm{zu}$ entschuldigen, daß er das Werk einer höheren Instanz («Tod») gewesen sei, oder dadurch, daß selbst die Opfer die Meisterschaft der Mörder zugeben mußten.

Worauf ist angespielt, wenn der Mann «träumet»: "der Tod ist ein Meister aus Deutschland »? Beachtet man in diesem Zusammenhang die Archaismen « singet » und «träumet » und die ebenfalls antiquierte Formulierung « er trifft dich mit bleierner Kugel », so verweist dies auf eine deutsche Tradition dieses Themas und führt zu der Frage, wo die Bewußtseinsstruktur vorgebildet sei, deren geschichtliche Wirksamkeit der «Mann" in dieser Fuge des «Meisters aus Deutschland» repräsentiert. Die 
Todesfuge läßt im übertragenen Sinn nicht nur an das in der Geschichte immer wieder <einsetzende> Thema der Judenpogrome denken, sondern auch an die <meisterhafte> $<$ Durchführung $>$ des Tötens in der deutschen Kunst.

Die Todesfuge wurde zuerst veröffentlicht 1948 in dem Band Der Sand aus den Urnen, und zwar mit einer Illustration von Edgar Jene, die allerdings wenig mit der Todesfuge, sondern eher mit einer Stelle in Eduard Mörikes Novelle Maler Nohen zu tun hat. Diese Stelle wiederum ist kaum auf das Gedicht beziehbar, wohl aber folgendes Lied ${ }^{11}$ :

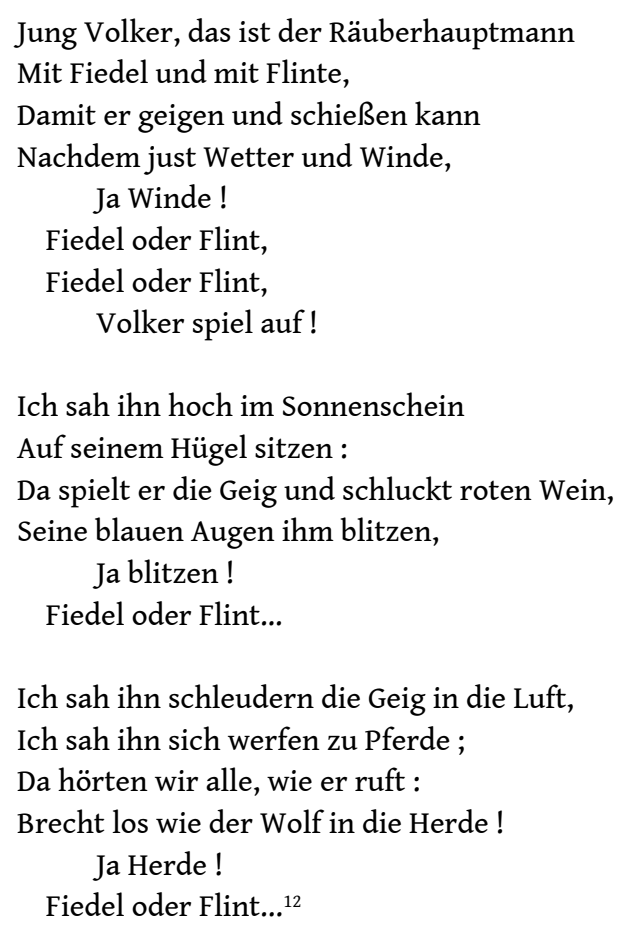

7 Auch hier ist die Perversion dargestellt, daß Kunst das Morden unterstützt : "Seine blauen Augen ihm blitzen ", und zwar während er geigt. Nicht nur Fiedel und Flinte sind hier vertauschbar, sondern auch Augen und Flinte, aus der es beim Schießen blitzt. Bezieht man die Todesfuge auf dieses Gedicht, wird nicht nur deutlich, daß dieser Volker eine Vorbildung des « Mannes » ist, sondern auch, daß sich " es blitzen die Sterne » auf die Augen des « Mannes » beziehen kann. Und was « Augensterne » zum Blitzen bringt, singen schon 160 Jahre vor dem Holocaust Schillers Räuber von den Bühnen :

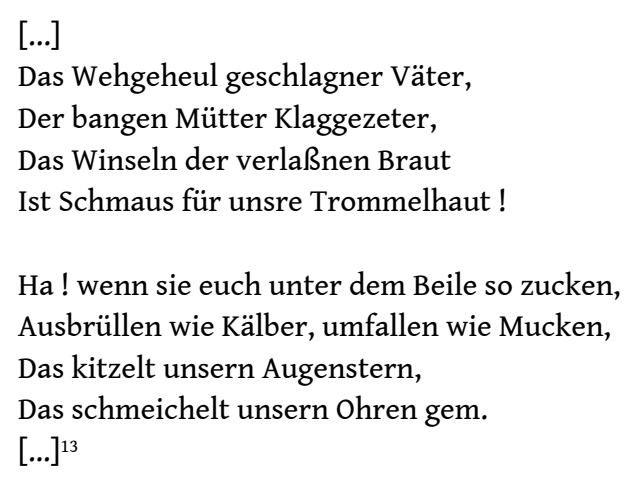

In Mörikes Novelle wird aber nicht nur die Geschichte des Räuberhauptmanns Jung Volker erzählt, sondern ist auch deren Rezeption gestaltet. Erzählt wird sie von einem Pfarrer, um seine Gäste zu ergötzen :

Räuber sag ich? Behüte Gott [!], daß ich ihm diesen abscheulichen Namen gebe, dem Lieblinge des Glücks, dem Lustigsten aller Waghälse, Abenteurer und Schelme, 
die sich jemals von fremder Leute Hab und Gut gefüttert haben. Wahr ists [!], er stand an der Spitze von etwa siebenzehn bis zwanzig Kerls, die der Schrecken aller reichen Knicker waren. Aber, beim Himmel [!], die pedantische Göttin der Gerechtigkeit selbst muß, dünkt mich [!], mit wohlgefälligem Lächeln zusehn, wie das verrufenste Gewerbe unter dieses Volkers Händen einen Schein von Liebenswürdigkeit [!] gewann. Der Prasser, der übermütige Edelmann und ehrlose Vasallen waren nicht sicher vor meinem [!] Helden und seiner verwegenen Bande, aber dem Bauern füllte er Küchen und Ställe. Voll körperlicher Anmut [!], tapfer, besonnen, leutselig und doch rätsel- haft [!], galt er bei seinen Gesellen fast für ein überirdisches [!] Wesen, und sein durchdringender Blick [!] mäßigte ihr Benehmen bis zur Bescheidenheit herunter ${ }^{14}$.

Schließlich «schien es, als flüsterte die Mutter Gottes vernehmliche Worte an sein Herz $»^{15}$. Zum Dank dafür soll er im Gelobten Land in ein Kloster gegangen sein ${ }^{16}$. Beachtenswert an dieser Erzählung ist, wie der christliche Erzähler sich mit seiner verbrecherischen Hauptfigur identifiziert und sie nicht nur liebenswürdig macht, sondern „seinen“ Helden mit der Unterstützung der « Mutter Gottes » einer gerechten Verurteilung entzieht. Hier ist mit christlicher Autorität gezeigt, wie ein Räuber und Mörder ("wie der Wolf in die Herde») als « überirdisches Wesen» bewundert sein kann. In dieser Tradition ist die Todesfuge erzählt. Auch hier wird der blauäugige Mörder als überirdisches Wesen bewundert, zum "Tod als ein Meister aus Deutschland » verklärt.

10 Diese - in der deutschen Bewußtseinsgeschichte nachweisbare - Bewunderung von Unrecht, wenn es in „faszinierender" Weise oder in „höheren“ Zusammenhängen geschieht, ist zentrales Thema der Todesfuge. Der Räuberhauptmann Jung Volker verweist mit seinem Namen auf Volker von Alzeye im Nibelungenlied ${ }^{17}$, den kühnsten Fiedler, dessen Saiten "suezlich » ertönten und der so gut mit der Waffe umging, daß es von ihm heißt : «sîn ellen zuo der fuoge diu beidiu wären grôz », d.h. " seine Kraft und sein Können (als Ritter) war so groß wie seine Kunstfertigkeit (als Künstler) ${ }^{18}$. Unter diesem Aspekt erscheint die "fuoge" dieses Helden im Begriff Todesfuge als (ästhetische) Kunstfertigkeit des Tötens wieder. Er fordert - im Lande der Hunnen! einen Hunnen, weil er etwas eleganter auftritt als die Burgunden, zu einem Kampf im Turnier, in welchem er ihn tötet. Noch in den fünfziger Jahren entschuldigt Helmut de Boor diese chauvinistische Anmaßung, die «Eleganz » eines ganzen Landes am eigenen Geschmack zu messen und Abweichungen tödlich zu bestrafen, indem er nicht den Täter, sondern das Opfer als «barbarisch» bezeichnet: "Der Hunne erscheint als moderner Frauendiener. Aber auch die Eleganz des Hunnenlandes ist barbarisch; sie läßt Sicherheit des Geschmacks, die mâze, vermissen. ${ }^{19}$ Und 1932 schreibt Paul Fechter in seiner Dichtung der Deutschen, im Nibelungenlied sei « auf Grund des durch keine Jahrhunderte christlicher Erziehung ausgerotteten heldischen Geistes der Nation [...] allem Morden und Sterben zum Trotz ein Werk entstanden, das in seiner dunkellodernden Pracht vielleicht in der ganzen Weltdichtung allein steht ${ }^{20}$. Diese «allem Morden und Sterben zum Trotz [...] dunkellodernde Pracht», verbunden mit dem Gedanken, in der Welt allein zu stehen, eben « Meister » zu sein, läßt sich in der Todesfuge erkennen.

11 Die Anspielung auf den Räuberhauptmann Jung Volker verweist aber auch auf den « Hauptmann » Karl Moor in Schillers Räubern, der sagt :

Ja, bei dem tausendarmigen [!] Tod [...] Der Gedanke verdient Vergötterung [!] Räuber und Mörder! [...] ich will mir eine fürchterliche Zerstreuung [!] machen ! [...] 
Glück zu dem Meister [!] unter euch, der am wildesten sengt [!], am gräßlichsten mordet [!], denn ich sage euch, er soll königlich belohnet werden [... $]^{21}$ verherrlichend entschuldigt werden, obgleich sie Mörder sind, wenn sie zugleich <liebenswürdig> erscheinen und sich mit irgendeiner Form höherer Notwendigkeit, also Tragik, in Verbindung bringen lassen. Wo die Anspielung auf diese Tradition nicht erkannt wird, kann die Todesfuge so rezipiert werden, daß die Judenvernichtung wie eine tragische Tat aussieht. Der " Mann» erscheint dann nicht nur als groß, weil er durch seine Nähe zum Tod überhöht ist, sondern weil er dem persönlichen (« dich ») Blick des Opfers im Namen einer höheren Idee («Deutschland») standhält. Dies wird noch deutlicher durch die Darstellung des zweiten Entlastungsthemas, das in der Todesfuge „erklingt".

17 Im Freischütz, "gewöhnlich als die erste rein deutsche Oper bezeichnet " ${ }^{25}$, fällt ein von Samuel gelenkter Schuß, dessen Kugel aber Agathe nicht trifft, weil diese durch geweihte Rosen dagegen gefeit ist. Stattdessen trifft die Kugel Kaspar, der mit Samuel im Bunde steht. In diesem « rein deutschen » Stoff ist also die Vorstellung gestaltet, daß selbst die Kugel des Bösen niemanden treffen kann, der unschuldig und deshalb von Gott geschützt ist. Dieser Aspekt ist in der Todesfuge vor allem 'thematisiert' durch Anspielungen auf das Alte Testament. 
Psalm 137 schildert eine Situation, die der in der Todesfuge vergleichbar ist :

An Babels Strömen sitzen wir [...] unsere Zwingherrn fordern Lieder dort von uns und heitre Klänge unsere Peiniger : « Ein Lied von Sion singet uns!» Wie könnten wir ein Lied dem Herrn zu Ehren in fremdem Lande singen?

19

Durch die Anspielung auf diese Situation ist den grausamen Befehlen des "Mannes » das Einmalige genommen, auch dadurch, daß es der jüdisch-christliche Gott selber war, der die Juden in diese Lage gebracht hat. Die zynische Vermischung von Mord und Kunst in Vernichtungslagern erscheint so gesehen von höchster Instanz autorisiert. Die Grausamkeiten des Holocaust werden in einem Bewußtsein, das sich der Verantwortung entziehen will, noch weiter entschuldigt, indem dieser Psalm (in der Übersetzung Luthers) mit den Worten schließt : «Wol dem, der deine [Babels] junge Kinder nimpt / Vnd zerschmettert sie an den stein." Wenn die persönliche Verantwortung für das eigene Handeln nicht die Grundlage für das Beurteilen von Schuld ist, dann tun Schufterle und seine deutschen Nachfolger nichts Schlimmeres, als es diese Juden anderen gewünscht haben. Die Todesfuge bietet durch das Erinnern an das Alte Testament immanent den Gedanken an, daß das jüdische Volk sich von Anfang an gegenüber seinem Gott mit Schuld beladen hat und daß dieser Gott selbst es ist, der die Juden durch den Holocaust bestraft.

Diese Vorstellung, daß Deutsche auserwählt sind, den Holocaust am auserwählten Volke zu vollziehen, wird noch dadurch überboten, daß der Mann «seine Juden» hervorpfeift. Denn das kann „rechtens“ nur der sagen, der die Juden zu seinem Volke auserkoren hat. Nun zeigt aber die Geschichte dieses Volkes, wie sie in der Bibel berichtet und im christlichen Bewußtsein gegenwärtig ist, daß Gott seine Juden trotz wiederholter Bestrafung nicht gebessert hat. Unter solchem Gesichtspunkt erscheint der Gott der Bibel als verhältnismäßig schwach, seinen eigenen Willen zu verwirklichen: Statt, wie er wollte, die ganze Menschheit einschließlich unschuldiger Kinder durch eine Flut zu ertränken, ließ er sich doch durch Noah verleiten, Ausnahmen zu machen. Und dennoch droht er seinem Volk immer wieder :

Drum werden jene wie ein Morgenwölkchen, wie Tau, der früh verschwindet [...] wie Rauch [!], der durch das Fenster zieht. (Osee 13,3.) - [...] mein Auge soll kein Mitleid haben, ich kenne keine Schonung mehr. (Ezechiel 8, 18. ) - [...] euer Bündnis mit dem Tod wird aufgehoben [...] Wenn des Verderbens Flut herflutet, vernichtet werdet ihr davon. (Isaias 28, 18).

21 An diesen kollektiven Drohungen gemessen handelte die SS, als ob sie das vollenden wollte, was Gott nicht gelungen war. So sagt Himmler in seiner berüchtigten Rede :

« Das jüdische Volk wird ausgerottet », sagt ein jeder Parteigenosse [...] Und dann kommen sie alle an [...], und jeder hat seinen anständigen Juden. [...] Von euch werden die meisten wissen, was es heißt, wenn 100 Leichen beisammen liegen, wenn 500 da liegen oder wenn 1000 da liegen. Dies durchgehalten und dabei [...] anständig geblieben zu sein, das hat uns hart gemacht. Dies ist ein niemals geschriebenes und niemals zu schreibendes Ruhmesblatt unserer Geschichte ${ }^{26}$.

Wenn die Rezipienten der Todesfuge den Satz «Der Tod ist ein Meister aus Deutschland » als Ersatz lesen für Isaias' « der Herr ist unser Meister " (Isaias 33, 22), dann wird der jüdische Gottesbegriff ersetzt durch den viel mächtigeren deutschen " Tod », und dieser wird dadurch entschuldigt, daß er nur vollstreckt, was der alte Gott längst angedroht hat.

Die in der Todesfuge gestaltete Hybris, Gott nicht nur gleich zu sein, sondern ihn zu übertreffen, verdeckt die Frage nach dem in der Bibel mehrfach so bezeichneten 
$<$ Meister> aus Judäa. Dieser Jesus, der von sich sagt, er sei das Leben, nicht der Tod, hat mit seinen Lehren wenig Folgen in der deutschen Bewußtseinsgeschichte gezeigt. Der „Volker" der Freiheitskriege, Theodor Körner, dessen Gedichtsammlung den Titel Leyer und Schwerdt erhielt (vgl. « Fidel oder Flint »), singt : «Das höchste Heil, das letzte liegt im Schwerdte", und weiß vom Gott der Deutschen: "Er will sein Volk in Waffenrüstung sehn ${ }^{27}$ (und zwar gegen die Franzosen, die als Christen ebenfalls auf diesen Gott vertrauen). Und schon bei Kleist heißt es - die Sintflut imitierend - :

Also auch, wenn alles unterginge, und kein Mensch [!], Weiber und Kinder mit eingerechnet, am Leben bliebe, würdest du den Kampf noch billigen? Antwort: Allerdings, mein Vater. Frage: Warum? Antwort: Weil es Gott lieb ist, wenn Menschen, ihrer Freiheit wegen, sterben ${ }^{28}$.

Die Symbiose von deutscher Ideologie und Altem Testament ist auch daran erkennbar, daß Sulamith mit keiner Gestalt aus dem Neuen Testament - etwa Maria - konfrontiert wird, sondern mit der deutschen Margarete aus deutscher Literatur. Denn wenn auch einerseits sich kaum Deutsche mit Juden identifizieren, so sind doch andererseits die Bücher der Juden, das Alte Testament, nicht weniger Teil deutschen Bewußtseins als die deutsche Dichtung Teil des Bewußtseins deutscher Juden ist. Dieses Neben- und Ineinander von Bewußtem und Unbewußtem ist ausgedrückt durch die chiastische Verschränkung von Margarete und Sulamith in Sein und Handeln des "Mannes »: « ein Mann wohnt im Haus dein goldenes Haar Margarete dein aschenes Haar Sulamith er spielt mit den Schlangen ». Entsprechend kann Mephistopheles in der Faust- Szene "Wald und Höhle" mit Versen aus dem Hohen Lied auf Sulamith anspielen, wo er Margarete meint (vgl. V. 3336 f.). Es wird in der Todesfuge "vorgeführt ", welche Widersprüchlichkeiten sich in diesem deutschen Bewußtsein nebeneinander vertragen und daß diese Widersprüchlichkeiten ihre Tradition, und, wenn sie nicht bewußt reflektiert werden, ihre inhumanen Konsequenzen haben. Denn schon die FaustRezeption hat es vermocht, Fausts rhetorische Frage, ob er nicht der « Unmensch » (V. 3349) sei, weil er « sie », nämlich Margarete, als « Opfer » (V. 3360 f.) zerstören müsse, als Ausdruck seiner Tragik zu verklären ${ }^{29}$. So sagt zum Beispiel Gundolf - indem er Faust und jungen Goethe sowie Gretchen und Friederike gleichsetzt -,

[...] daß Goethes Leben und Schaffen [...] unvergleichlich wichtiger vor Gott und Welt ist als tausend [!] Friederiken [...] Faust [der « Opferer »], nicht Gretchen [die «Geopferte »] ist der tragische Mittelpunkt der Gretchentragödie, wenngleich freilich auch die Tragik des Faust um so tiefer ist, je tiefer die Tragödie seines Opfers mitgefühlt wird [...] $]^{30}$

Das einleitende Oxymoron «Schwarze Milch» ist das Signal für das widersprüchliche Bewußtsein, dessen künstlerische „Verarbeitung“ in dieser „Fuge“ so weit getrieben wird, daß am Schluß die Widersprüche fast verschwinden, indem Sulamith und Margarete so schwesterlich vereinigt erscheinen, als ob nichts geschehen sei, oder wie Peter Seidensticker es unkritisch nennt - als «Ausdruck schicksalhafter Verstrickung der Macht mit ihrem Opfer » :

In der Engführung dieser beiden Stimmen [...] kulminiert die Spannung des Gedichtes. Im Rhythmus der Sprache erscheint die musikalische Dynamik der Fuge als Tanzbewegung, die die Personen als Träger der Themen miteinander ausführen. [...] Im Tanz vollzieht sich auch die Vereinigung der Todgeweihten mit dem Herrn ihres Schicksals. [...] Hier wird die zwielichtige Gestalt des Fremdlings als Herr über eine graue, einförmige Schar von Todgeweihten in den Bann des Tanzes seiner Opfer, den sie auf sein Geheiß beginnen, hineingerissen, und indem er sich in ihren Gefährten verwandelt, verliert er die Gewalt über sie [... $]^{31}$ 
Sätze belegen exemplarisch, daß ihr Verfasser unreflektiert das Bewußtsein reproduziert, das in der Todesfuge zur kritischen Disposition gestellt ist, man könnte auch sagen, er tritt in die 'Falle', die die Todesfuge darstellt. Der Täter wird zum « Herrn ihres Schicksals» erhöht, ist aber gleichzeitig selbst in einer "schicksalhaften Verstrickung" gefangen, er ist der «Herr über eine graue, einförmige Schar von Todgeweihten", ohne daß darüber nachgedacht würde, wer denn diese euphemistisch als «Schar » bezeichneten - «Opfer » zu Tode weiht. Dafür kann nur eine noch höhere Instanz zuständig sein, die schließlich nichts dagegen hat, daß der Opferer sich zum "Gefährten" seiner "Opfer» verwandelt und so selber zum bedauernswerten Opfer wird, das - leider ? - « die Gewalt über sie » verliert.

Anhand solcher schwammigen, für den Deutschunterricht bestimmten Formulierungen läßt sich erkennen, wie genau in diesem Gedicht seine eigene Rezeption gestaltet ist. Es enthält die "Versuchung“, sich von seinem "Rhythmus der Sprache", von der "musikalischen Dynamik der Fuge als Tanzbewegung", von seiner vielgepriesenen Schönheit einlullen zu lassen. Ich habe zu zeigen versucht, daß und warum dieses Gedicht als Lobpreis des « Todes ", des « Meisters aus Deutschland », sich hervorragend eignet, um den Holocaust zu beschönigen, um nicht zu sagen: zu genießen. Eine satirische Komponente erhält es erst, wenn man sich das in ihm enthaltene EntSchuldungs-Angebot erarbeitet hat. Dann kann das Gedicht gelesen werden, als ob es nicht nur satirisch dar- auf <anspielte>, unter welchen ideologischen Voraussetzungen der Holocaust möglich war, sondern auch im voraus kritisierte, wie man in Deutschland die eigene Geschichte rezipieren werde. Als die wesentlichen Momente dieser Kritik erweisen sich : die Vermengung der Täter mit den Opfern und die Relativierung der eigenen Barbarei durch das Anspielen auf die barbarischen Taten des biblischen Gottes, beides damit verbunden, daß der Holocaust möglichst nicht unter moralischen, sondern ästhetischen Kategorien aufgearbeitet wird.

Dabei könnte bedeutend sein, daß in der Todesfuge zwar auf Altes und Neues Testament angespielt, aber unmittelbar von Gott nicht gesprochen und somit nicht explizit die Möglichkeit eingeräumt wird, in irgendeinem höheren Sinne hätte auch Barbarei ihr Gutes. Wo immer Gott als Herr der Geschichte gedacht ist, sind die Mörder entschuldigt.

Paul Celan konnte dies alles - gewollt oder ungewollt - vermutlich deshalb darstellen, weil er als deutscher Jude auch diese «schwarze Milch» deutscher Todes-, genauer : Mörder-Ästhetisierung " getrunken » hat ${ }^{32}$.

\section{NOTES}

1. Zitat aus : Raddatz, Fritz J. : Brecht konnte mich nicht riechen. Ein ZEIT-Gespräch mit Günther Anders. In : DIE ZEIT. Nr. 13. 22. März 1985. S. 65-67 ; S. 67.

2. Härtung, Peter : Für die konstante Anarchie. In : Akzente 20.1973. S. 81- 91 ; S. 84. 
3. Zitat aus : Müller-Münch, Irmgard : Es gibt keine Sünde, die nicht verziehen werden kann. Martin Bormann über seinen Vater, Hitlers Sekretär Martin Bormann. In : Frankfurter Rundschau. Nr. 127. 3. Juni 1996. S. 12.

4. Alle Nachweise dazu in : Stiehler, Heinrich : Die Zeit der Todesfuge. Zu den Anfängen Paul Celans. In : Akzente 19. 1972. S. 11-40 ; S. 29 und 36.

5. «Die Todesfuge [...] gehört zu den vollkommenen und faszinierenden Gedichten unserer Zeit ; es wird kaum jemand geben, der nicht beim ersten Hören oder Lesen davon gepackt wird.» (Butzlaff, Wolf gang: [Zu Paul Celans Todesfuge] In: Der Deutschunterricht 12. 1960. Heft 3. S. 42-51; S. 42).

6. Stiehler, a.a.O., S. 27.

7. Dieses « seine Juden » könnte von einem « wir » als lyrischem Subjekt des Gedichts und Opfer des Holocaust nur ironisch gesagt sein; wollte man aber die Aussagen der Opfer als ironische auffassen, dann wäre es mit der Ernsthaftigkeit des Gedichts vorbei. Auch hier ist es also hilfreich, von einem Erzähler auszugehen.

8. Deutsches Wörterbuch von Jacob und Wilhelm Grimm. Band 11,1, 1. Leipzig 1935. Sp. 119.

9. Obgleich es sich streng genommen nur um eine quasianagrammatische Beziehung handelt, verwende ich hier und in vergleichbaren Fällen diesen Begriff.

10. Es gibt noch den Binnenreim « befiehlt » und « spielt » (« er befiehlt uns spielt auf nun zum Tanz»), der die im ganzen Gedicht präsente Übereinstimmung des Widersprüchlichen repräsentiert, und den Binnenreim « ruft ... Luft » (25), der auf den gleichlautenden Endreim in Mörikes Gedicht Jung Volker anspielt, das im folgenden zitiert und auf die Todesfuge bezogen wird.

11. Auf diese Zusammenhänge wird aufmerksam gemacht in : Wiedemann-Wolf, Barbara : Antschel Paul - Paul Celan. Studien zum Frühwerk. Tübingen 1985. S. 84. Die Zeichnung Jenes ist wiedergegeben in : Könneker, Sabine : "Sichtbares, Hörbares ». Die Beziehung zwischen Sprachkunst und bildender Kunst am Beispiel Paul Celans. Bielefeld 1995. S. 175 .

12. Mörike, Eduard : Maler Nohen. In : E.M. : Werke in einem Band. Hrsg. von Herbert G. Göpfert. München 1977. S.325-720 ; S. 605 f.

13. Schiller, Friedrich : Die Räuber. In: F. Sch. : Sämtliche Werke. Bd. 1. Hrsg. von Gerhard Fricke und Herbert G. Göpfert. 6. Auflage. München 1980. S. 481-618 ; S. 585 f. [IV, 5].

14. Mörike, a.a.O., S. $600 \mathrm{f}$.

15. Mörike, a.a.O., S. $602 \mathrm{f}$.

16. Vgl. Mörike, a.a.O., S. 604.

17. Die Funktion des «Mythos von Gefolgschaftstreue und Vaterlandsliebe »im Nibelungenlied als «ideologischer Rückhalt » des Nationalsozialismus ist thematisiert in einem frühen Gedicht Celans, Russischer Frühling, das mit den Versen endet: «Träumerisch hält meine Hand und singt in die wallende Bläue / für alle, die hier liegen, Herr Volker von Alzey. » (Stiehler, S. 15).

18. Das Nibelungenlied. Hrsg. von Helmut de Boor. 18. Auflage. Wiesbaden 1965. S. 289. [Str. 1834-35. ]

19. Kommentar zum Nibelungenlied. In : Das Nibelungenlied, a.a.O., S. 296.

20. Fechter, Paul : Dichtung der Deutschen. Berlin o. J. [1932]. S. 82.

21. Die Räuber, a.a.O., S. 515. [1,2].

22. Die Räuber, a.a.O., S. 547. [II, 3].

23. Die Räuber, a.a.O., S. 563 f. [III, 2] - Ich setze hier eine unreflektierte Rezeption der Räuber voraus, wie sie etwa der unreflektierten Rezeption der Todesfuge entspricht und 
wie sie bis in die Nachkriegszeit gepflegt wurde. Zum Beispiel schreibt Gerhard Storz : «Wohl hat er [Karl] noch furchtbare Schläge zu leiden : Verzweiflung und Tod des Vaters, Verlust [...] der Geliebten, der er selbst den Tod zu geben verdammt wird. » Auch hier ist die Sympathie beim Täter : nicht er ermordet seine Geliebte, sondern er <verliert sie>, indem er dazu « verdammt » wird, ihr « den Tod zu geben », und weil er « ehrfürchtig » die «Übermacht der oberen Mächte» erkennt, bleibt ihm « die Gnade der freien büßenden Tat». «Allein [!] das Ewige und Göttliche bezeugt sich als gültig und herrschend [!?!]. Das ist die klare und einfache Grundlinie der so dichten und so bewegten Handlung des Dramas. » (In : Schiller, Friedrich : Dramen und Gedichte. Hrsg. von der Deutschen Schillergesellschaft. Stuttgart 1955. S. 16. [Volksausgabe (Auflage : 100 000), die vor allem für die Jugend gedacht und für 5 DM in den Schulen zu haben war.]).

24. Schiller, Friedrich : Zerstreute Betrachtungen über verschiedene ästhetische Gegenstände. In : F. Sch. : Sämtliche Werke. Bd. 5. Hrsg. von Gerhard Fricke und Herbert G. Göpfert.6. Auflage. München 1980. S. 543-569 ; S. 549.

25. Reclams Opernführer. Hrsg. von Wilhelm Zentner. 26. Auflage. Stuttgart 1973. S. 114.

26. Zitiert nach: Hof er, Walther (Hrsg.): Der Nationalsozialismus. Dokumente 1933-1945. Frankfurt 1960. S. 114.

27. Zitiert nach: Binder, Alwin, und Dietrich Scholle: Deutsche politische Lyrik vom Mittelalter bis zum Vormärz. Teil II : Text- und Arbeitsbuch. Frankfurt 1975. S. 64.

28. Ebda,S. 70.

29. Vgl. : Binder, Alwin : Seiner Rede Zauberfluß. Uneigentliches Sprechen und Gewalt als Gegenstand der Faust-Szene «Wald und Höhle ». In : Goethe-Jahrbuch 106. 1989. S. 211-229.

30. Gundolf, Friedrich : Goethe. Berlin 1920. S. 144-146.

31. Seidensticker, Peter : [Zu Paul Celans Todesfuge] In : Der Deutschunterricht 12. 1960. Heft 3. S. 35-42; S. $41 \mathrm{f}$.

32. Daß dieser Dichter in deutsche Geschichte und deutsche Ideologie 'involviert' war, ist - seltsamerweise - dadurch „abgebildet“, daß sowohl sein echter Name Antschel wie dessen anagrammatische Form Celan in «Deutschland »- ebenfalls anagrammatisch - zu erkennen sind (dEuTSCHLANd > ANtsChEL > CELAN).

\section{RÉSUMÉS}

Paul Celans Todesfuge ist ein außergewöhnlicher Text der Nachkriegszeit: Kaum ein anderes Gedicht dürfte in (West-)Deutschland so bekannt sein, und zu kaum einem anderen Gedicht gibt es so viele Interpretationen wie zur Todesfuge. Irritierend an dieser Rezeption ist jedoch der fast allgemeine Konsens, dieses Gedicht beschreibe den Holocaust und sei zugleich schön. Deshalb wird gefragt : Ist in diesem Gedicht nicht eher die deutsche Rezeption des Holocaust als dieser selbst gestaltet? Was fasziniert ein deutsches Publikum, wenn es dieses Gedicht über die Barbarei des Holocaust schön findet ? Durch welche Bewußtseinstraditionen ist diese Rezeption vorbereitet? Es wird gezeigt, daß die Todesfuge Anspielungen auf mehrere «Meister aus Deutschland » enthält, die Mörder sind und trotzdem Hebens- und bewunderungswürdig bleiben. Auch Anspielungen auf die Bibel werden in die Interpretation einbezogen, die zu dem Ergebnis 
kommt, daß in diesem Gedicht eher der Umgang mit dem Holocaust als dieser selbst gestaltet ist und dabei satirisch 'vorgeführt' wird.

Le poème Todesfuge (La Fugue de la mort) de Paul Celan est un texte étonnant de l'après-guerre : probablement aucun autre poème ne jouit d'une telle notoriété en Allemagne (de l'Ouest) et aucun autre poème n'a fait l'objet d'aussi nombreuses interprétations que celui-ci. Mais ce qui est surprenant dans cette réception, c'est que pratiquement tout le monde s'accorde pour dire que ce poème décrit l'holocauste et est en même temps d'une grande beauté. D'où la question : ce poème n'exprime-t-il pas plutôt la réception de l'holocauste que l'holocauste lui-même ? Qu'estce qui fascine le public allemand, lorsqu'il trouve beau ce poème sur la barbarie de l'holocauste? Quelles traditions dans l'histoire de la conscience ont frayé le chemin à cette réception ? L'étude montre que le poème Todesfuge contient des allusions à plusieurs "grands maîtres de l'Allemagne », qui, tout en étant des meurtriers, n'ont cessé de susciter l'estime et l'admiration. Les allusions bibliques sont également intégrées dans cette interprétation qui aboutit à la conclusion que ce poème exprime plutôt le rapport à l'holocauste que l'holocauste lui-même et qu'il le « représente »sur le mode satirique. 